\title{
The Study of Functional and Pasting Properties of Taro "SEMIR" (Colocasia esculenta L. Schott) Starch Modified by Various Thermal Process
}

\author{
Endah Wulandari *, Herlina Marta, Elazmanawati Lembong, and Fransiska Ariela \\ Department of Food Industrial Technology, Universitas Padjadjaran, Jl. Raya Bandung-Sumedang KM 21, \\ Jatinangor, Sumedang, West Java, 45363, Indonesia \\ ${ }^{*}$ Corresponding author email: endah.wulandari@unpad.ac.id; Tel: 081320947396 \\ Type of the Paper (Article) \\ Received: 2018-06-04; Accepted: 2018-07-19; Published: 2018-07-25 \\ https://doi.org/10.29253/jptafm.1.1.2018.6
}

\begin{abstract}
Taro tubers locally known as Semir are potentially used as a source of starch. Taro Semir starch can be used as a substitute of rice flour in the raw material of rice vermicelli. However, native taro starch has not been optimally utilized due to poor functional and poor pasting properties. Thus, further treatment is needed to improve their properties. The ideal characteristics of starch as a raw material of vermicelli are low swelling volume, stable against heating and stirring, and fast-rising value of setback viscosity. The aim of this research was to determine a suitable physical modification to produce functional and pasting properties of taro Semir starch. The physical modifications were applied in preparing taro Semir starch includes Heat Moisture Treatment (HMT) at $110^{\circ} \mathrm{C}$ for 8 hours, Heat Pressure Treatment (HPT) at $120^{\circ} \mathrm{C} 1$ hour, Microwave Heat/Moisture Treatment (MWT) with $100 \mathrm{~W}$ 20 minutes, and Osmotic Pressure Treatment (OPT) at $120^{\circ} \mathrm{C} 30$ minutes. Those modified taro Semir starch were compared with the native taro Semir starch. Taro Semir starch modified by HMT revealed with the best performance compared to others modification. The obtained characteristic of this starch were swelling volume of $6.57 \pm 0.80 \mathrm{~mL} / \mathrm{g}$, solubility of $5.80 \pm 0.29 \%$, water absorption capacity of $2.59 \pm 0.09 \mathrm{~g} / \mathrm{g}$, gel strength of $3,518 \pm 0.17 \mathrm{gF}$, syneresis percentage of $5.39 \pm 2.31 \%$, pasting temperature of $83.65 \pm 0.77^{\circ} \mathrm{C}$, peak viscosity $4,349.17 \pm 192.61 \mathrm{cP}$, breakdown viscosity $494 \pm 33.81 \mathrm{cP}$, and setback viscosity of $2,413 \pm 165.85 \mathrm{cP}$. It was concluded that $\mathrm{HMT}$ at $110^{\circ} \mathrm{C}$ for 8 hours considered as the best method of modification for the Taro Semir starch.
\end{abstract}

Keywords: taro, starch, modification, functional properties, pasting properties

\section{Introduction}

Taro as food material is quite popular in Indonesia and available in a high quantity especially from taro production centers in Papua and Java (Bogor, Sumedang, and Malang). Taro Semir (Colocasia esculenta L. Schott) is the one type of taro becomes the main agricultural commodities in Sumedang, West Java, Indonesia. The production of taro Semir in this region is considered high enough with the production reached up to 3.539 tons in 2014. However, Taro Semir as a potential type of taro received less attention from the public. In addition, taro Semir can be used as a source of starch provided further investigation to meet the required starch characteristics [1]. Fresh taro is easily damaged during storage 
due to a high-water content of $63-85 \%$ like other fresh food. Thus, the effort on the taro processing usually aims to extend the shelf life which is recently only limited to boiling, steaming, and making taro chips products. Indeed, taro can be processed into intermediate products such as starch by introducing a process to improve the starch content in taro (70-80\%). Furthermore, effort on extending shelf life to a starch encourages the emergence of more diverse products and the development of starch-based industries which in turn increase the selling value of taro commodities [2].

Taro starch can be used as a substitute for rice vermicelli which is processed food such as noodles made from nongluten. Vermicelli is made from rice flour and noodles. Vermicelli also made from starch such as tuber (potato, sweet potato, and tapioca), green bean, ganyong, palm and sago starches. The taro starch has not yet widely utilized as a raw material of the product due to its poor starch characteristics. The ideal starch characteristics are low starch swelling ability, stable against heat and stir, and rapid setback viscosity [3-4]. Taro starch generally poses a temperature gelatinization varying between $54.4-85.5^{\circ} \mathrm{C}$ [5-7] which is higher compared to potato starch and cassava starch [8]. However, it has several deficiencies such as high starch swelling, unstable to heating and stirring, and weak setback viscosity $[6,9,10]$.

In order to obtain ideal starch characteristics for the vermicelli products, the physical modification process of Heat Moisture Treatment (HMT) proposed by many researchers. This modified method is a hydrothermal process with heating of starch granules above the glass transition temperature for a long period of time (1-24 hours). In addition, this process takes place at a limited moisture content $(<35 \%)$ and high temperature $\left(80-140^{\circ} \mathrm{C}\right)$. The obtained characteristics of starch are low swelling volume, being stable against heating also stirring and a rapid setback viscosity [3,11]. The HMT modification may restrict the capacity of starch swelling, decrease the value of breakdown and increase the value of setback on sweet potato starch and rice starch to allow the application in vermicelli $[3,11]$. In addition, this method able to improve the characteristic of starch sticks by a simple and environmentally safe process [12].

Others developed physical modification methods are the Heat Pressure Treatment (HPT), the Microwave Heat/Moisture Treatment (MWT), and the Osmotic Pressure Treatment (OPT). The HPT is a modification of starch by a heating process under high-pressure steam. The MWT is a modification by using a device with nonionized energy and vibration of electromagnetic molecules at high frequencies capable to raise the temperature rapidly and homogeneously penetrated into the starch. The OPT is a modification method by initially preparing a starch suspension in a saturated sodium sulfate solution followed by a drying process at a temperature between $100-120^{\circ} \mathrm{C}$ [13]. The HPT and MWT methods are known to decrease swelling volume, breakdown values, and increase setback value on cassava starch and potato starch [14]. In addition, the OPT method not only decreases swelling volume and breakdown value but also decreases the setback value on cereal starch [15].

To the best knowledge of the authors, the information about the functional properties and the profile of starch made from taro Semir starch remain very limited to compare with the various application of modified methods such as HMT, HPT, MWT, and OPT. Therefore, this recent investigation aims to determine the effect of taro Semir starch modification by HMT, HPT, MWT, and OPT methods to the functional properties and gelatinization profile of the starch.

\section{Materials and Methods}

The materials used in this investigation were a taro Semir received from varieties with 12 months harvest age (received from Sumedang, West Java, Indonesia), distilled water and sodium sulfate $\left(\mathrm{Na}_{2} \mathrm{SO}_{4}\right)$ received from Merck. The physical modifications were applied in preparing taro Semir Starch with various methods includes Heat Moisture Treatment (HMT) at temperature of $110^{\circ} \mathrm{C}$ for 8 hours, Heat Pressure Treatment (HPT) at temperature of $120^{\circ} \mathrm{C} 1$ hour, Microwave Heat/Moisture Treatment (MWT) with $100 \mathrm{~W}$ for 20 minutes, and Osmotic Pressure Treatment (OPT) at temperature of $120^{\circ} \mathrm{C}$ for 30 minutes. The functional properties were evaluated based on the measurement of swelling volume and solubility, water absorption capacity, gel strength and freeze-thaw stability [3]. The pasting properties and gelatinization profile obtained from Rapid Visco Analyzer (RVA) [3] consists of the initial gelatinization temperature, peak viscosity, breakdown viscosity, and setback viscosity. The statistical analysis was done by analyzing the experimental data using one-way analysis of variance (ANOVA) followed by Duncan's multiple range test $(\alpha=0.05)$. 


\section{Results and Discussion}

\subsection{Functional Properties}

\subsubsection{Swelling Volume}

Table 1 showed the swelling volume of native and physical-modified taro Semir starch. Taro Semir starch obtained from modified treatment showed a significantly different compared to native taro starch. The result of modified treatment showed a decreased swelling volume. This decreased was influenced by the improved interaction between amylose and amylopectin caused strengthening the intramolecular bond, and the change of crystalline arrangement in starch [16]. The decrease in swelling volume was also influenced by the formation of the amylose and lipid complexes presented in starch inhibited the development of granules during the modification process [17]. Amylose was able to form complexes with free fatty acids, glycerides fatty acid components, iodine, and some alcohols [16]. Taro Semir starch obtained from the modification of HMT and HPT gave significantly different effect compare to taro starch obtained from the modification of MWT, OPT, and its native starch, as shown in Table 1.

Swelling volume of taro Semir starch obtained from HMT modification was not significantly different compared to the HPT modification. Similarly, the swelling volume of taro Semir starch obtained from MWT modification was not significantly different from the treatment of pseudo-modification (HPT). The decrease of swelling volume of the starches obtained from HMT and HPT modifications were higher than from MWT and OPT modifications. These were might due to the level of damage to starches granules induced by HMT and HPT modifications were higher than from the MWT and OPT modifications. This was in agreement to the reported study of [1], that the HMT process provides cracking and inner forming of the taro starch granules affected by the prolonged treatment (16 hours) and the limited moisture on the treatment restricted gelatinization. The effect of this process occurs only on the concentric rings on the outside of the granule. Therefore, the uninterrupted original granules become more crystalline and stable. In addition, the HPT modification in the study also resulted in the presence of polymers that melt on taro starches. The study showed that the HPT modification generated major damage to the starch granules due to high temperature and pressure.

Table 1. Swelling volume of native and physical-modified taro Semir starch

\begin{tabular}{cc}
\hline Treatment & Swelling Volume $(\mathbf{m L} / \mathbf{g ~ d b})$ \\
\hline Native & $10.67 \pm 0.44 \mathrm{c}$ \\
HMT & $6.57 \pm 0.80 \mathrm{a}$ \\
HPT & $6.47 \pm 0.97 \mathrm{a}$ \\
MWT & $8.62 \pm 0.46 \mathrm{~b}$ \\
OPT & $8.57 \pm 0.66 \mathrm{~b}$ \\
\hline
\end{tabular}

Note: The average values of treatments marked with the same letters show no significant difference at the $5 \%$ test level according to Duncan's multiple range test.

The starch obtained from MWT and OPT modifications did not provide a significant swelling volume change compared to start from the HMT and HPT modifications. The swelling volume given from OPT did not as significant as from the HPT. This may due to the heating process in an autoclave was only for 30 minutes. It was reported that HPT modification produces holes in some corn starch granules, while the OPT modification produces holes with the formation of wrinkles and donut shape [15]. Similarly, the result of the MWT modification produces a slight change in the shape of the starch granules to be slightly more aggregated than the native starch. Therefore, it was emphasized that significant swelling volume change in the HMT and HPT may due to the morphological changes occurred significantly.

Furthermore, the HMT modification decreased the swelling volume due to the temperature process causing rearrangement of the starch crystalline portion and amorphous structure changes [18]. The energy absorbed during HMT heating unfolded the double helix of amylopectin and facilitated the regulation or formation of new intermolecular bonds. Similarly observed that the decreased the swelling volume occurred on the starch obtained from HPT modification. The HPT modifications suppressed starch granules rapidly created bonds between molecules in the associated starch resulted in the stronger bonds [8]. Similarly reported from a previous investigation [14] that the HPT modification 
on Dioscorea alata starch with $30 \%$ moisture content at a temperature of $120^{\circ} \mathrm{C}$ for 1 hour resulted in the decrease of the swelling volume.

The decrease of swelling volume of the starch obtain from MWT modification was not as large as to the starch obtain from HMT and HPT modifications. The decreased of swelling volume of the taro Semir starch obtained from MWT modification might due to the radiant energy improved the hydrogen bond strength of the starch granules established from the interaction between the amylose-amylose chain and amylose-amylopectin. The decrease in swelling volume was also caused by the rearrangement of the crystalline area of the starch granules. The decrease in the swelling volume was also occurred due to MWT application for three types of maize starch, reported elsewhere [19]. Similar to the MWT, the OPT also did not decrease the swelling volume significantly compared to the starch obtained from HMT and HPTmodifications. The decrease of swelling volume of the starch received from the OPT might due to $\mathrm{Na}_{2} \mathrm{SO}_{4}$. Also, the presence of high pressure and temperature suppressed the bond between starch molecules. Anions in salt contributed more effects than cations. The $\mathrm{SO}_{4}{ }^{2-}$ ions protected the starch granules by strengthening hydrogen bonds of the starch molecules. Thus, the presence of these ions stimulated in a decrease of swelling volume [20]. Similar to HPT modification was also influenced by steam pressures that suppressed the starch granules caused the bonds in the starch molecule change. Indeed, this OPT modification was performed only for 30 minutes resulted in a swelling volume incomparable to the starch obtained from the HPT modification performed for 1 hour. Similarly, it was reported for the decrease of the swelling volume of the cornstarch by OPT modification at a temperature of $120^{\circ} \mathrm{C}$ for $30 \mathrm{~min}$ [15].

\subsubsection{Solubility (Amylose Leaching)}

Taro Semir starch obtained from HPT, MWT, and OPT modifications generated a significantly different effect on solubility compared to native taro sSmir starch and taro Semir obtained from HMT modification, as shown in Table 2. However, the change of the amylose leaching property of the starch received from HPT, MWT, and OPT modifications did not significantly observe. It was suspected that the pressure on the HPT and OPT modifications caused remarkable changes of the amorphous parts. The radiation energy of the MWT greatly affects the amorphous portion. Improvement on the amorphous area of the starch might due to the increased of amylose leaching for all three treatments. In contrast, the effect of amylose leaching on the OPT modification was quite significantly different compared to other treatments, the effect of amylose leaching for those others three treatments considered insignificant. The starch obtained from OPT modification caused an increase in the amorphous area of the starch granules leads to more susceptible to water-soluble than the crystalline area. Therefore, the larger amorphous area generated a higher leaching amylose [15]. This result was in agreement to the reported study on cornstarch and potato starch treated by OPT modification for $30 \mathrm{~min}$ [2].

Table 2. Amylose leaching of native and physical modification of the taro Semir starch

\begin{tabular}{cc}
\hline Treatment & Amylose Leaching (\%) \\
\hline Native & $5.42 \pm 0.65 \mathrm{a}$ \\
HMT & $5.80 \pm 0.29 \mathrm{a}$ \\
HPT & $8.02 \pm 0.65 \mathrm{~b}$ \\
MWT & $7.13 \pm 0.08 \mathrm{~b}$ \\
OPT & $8.17 \pm 1.08 \mathrm{~b}$ \\
\hline
\end{tabular}

Note: The average values of treatments marked with the same letters show do not a significant difference at the $5 \%$ test level according to Duncan's multiple range test.

The amylose leaching of starch obtained from HPT modification was increased compared to the native starch. This was due to the HPT modification provided the most noticeable large amorphous area of the starch molecule. This result was in agreement to the reported study [21] on taro starch obtained from HPT modification with $25 \%$ moisture content at $110^{\circ} \mathrm{C}$ for 1 hour. However, these results did not in accordance to the reported HPT modification on Dioscorea alata [8], on cassava and pinhao starches [14] in which decrease on the amylose leaching. According to ref. [8], the pressure on HPT modification compressed the starch granule structure hinders the mobility of the soluble amylose molecule. The increase of amylose leaching observed in HPT modification formed a hole in the starch granules caused easily disintegrated. 
Similarly, the MWT modification also offered a tendency of increasing the amylose leaching compared to native starch. This increase in amylose leaching might due to radiation energy caused the widening of the amorphous area [22]. The most preferable state of the water-soluble amylose was in the amorphous area of the free form or bound to fat $[19,23]$. The energy emitted by the microwave for 10 minutes was sufficient to cut the branch of amylopectin into a smaller fraction or a straight chain polymer initiate structural changes to enable water to get into the starch. This result was in agreement to the study of taro starch obtained from MWT modification reported elsewhere [21].

The HMT modification for the native taro starch did not provide a significant effect on the amylose leaching. This might due to the HMT modification occurred only on the concentric rings of the outside granule caused less effect on the original granules to create more crystalline formation and stable [1]. A strong interaction of amylose or amylopectin prevented amylose leaching occurred. Generally, the HMT modification caused a decrease in the starch amylose leaching, though did not always derive a significant decrease. The HMT modification on the sweet potato starch decreased the properties of amylose leaching, but this process on sweet potato starch increased the amylose leaching as reported elsewhere [3]. The different properties of amylose leaching received from various treatments may due to the molecular structure of amylopectin (chain length, branching, molecular weight, and polydispersity), starch composition (amylose-amylopectin ratio, amylose-lipid complex, and phosphorus content), and granular structure (ratios of crystalline-amorphous regions). Also, the different properties of amylose leaching influenced by water content, temperature, and duration of the treatment.

\subsubsection{The Water Absorption Capacity}

The treatments on native starch increased the capacity of water absorption of the starch as shown in Table 3. The taro Semir starch obtained from HMT, MWT, and OPT modifications received a significant effect compared to the native taro starch and starch obtained from HPT modification.

Table 3. The water absorption capacity of native and modified taro Semir starch

\begin{tabular}{cc}
\hline Treatment & The Water Absorption Capacity (g / g db) \\
\hline Native & $1.47 \pm 0.04 \mathrm{a}$ \\
HMT & $2.59 \pm 0.09 \mathrm{~b}$ \\
HPT & $3.85 \pm 0.25 \mathrm{c}$ \\
MWT & $2.51 \pm 0.13 \mathrm{~b}$ \\
OPT & $2.43 \pm 0.27 \mathrm{~b}$ \\
\hline
\end{tabular}

Note: The average values of treatments marked with the same letters show no significant difference at the $5 \%$ test level according to Duncan's multiple range test.

The alteration of water absorption capacity of the starch received from HPT modification might due to a high temperature and pressure of the HPT modification generated cracking and forming the secondary inner granules on the taro starch [1], and even created holes in some corn starch granules [15]. In contrast, the HMT, MWT, and OPT modifications produced a starch with an insignificant alteration of water absorption capacity. This may due to the remarkable damage of starch granules were observed $[1,15]$ and revealed to relatively similar water absorption capacity.

The taro Semir starch obtained from HMT modification received higher water absorption capacity compared to the native starch. This HMT modification improved the starch hydrophilic properties caused by adsorption of some hydrogen bonds to the boundary between the amorphous and the crystalline area. Similarly, also reported in ref [20] on the HMT modification to the starch with $25 \%$ moisture content at a temperature of $110^{\circ} \mathrm{C}$ for 3 hours. Similarly, also observed for the starch obtained from the MWT modification increased in water absorption capacity. Structural changes of the starch by microwaves radiation allowed water easily to get into the starch granules.

The starch obtained from the HPT modification provided the highest water absorption capacity compared to other treatments. According to ref [8], during the pressurization process of HPT modification, the damage to intramolecular hydrogen bonds occurs. The hydrogen bonds played a role in maintaining the structure of granular integrity and transformed into free hydroxyl groups function water absorber. This indicated that the HPT modification was capable of producing more hydroxyl groups than other treatments. 
The increase on the water absorption capacity for the starch obtained from OPT modification assumed due to the ions in $\mathrm{Na}_{2} \mathrm{SO}_{4}$ salts capable on weakening the bond of the starch molecules [24] where the cationic ions were more dominant than anionic ions [24].

\subsubsection{The Gel Strength}

Taro Semir starches obtained from modified treatments offered gel strength significantly different compared to native Semir taro starch as shown in Table 4.The gel strength was caused primarily by retrogradation that was more affected by the presence of amylose than amylopectin [14]. It was also suggested that the increase of amylose leaching lead to the increase of gel strength and high granular solubility, the gel become harder due to the release of amylose to form the gel matrix [25]. However, the increase or the decrease of the solubility allows the increase in gel strength [11].

Table 4. The gel strength of native and modified taro Semir starch

\begin{tabular}{cc}
\hline Treatment & Gel Strength $\mathbf{~ g F ) ~}$ \\
\hline Native & $2,984 \pm 0.09 \mathrm{a}$ \\
HMT & $3,518 \pm 0.17 \mathrm{a}$ \\
HPT & $3,036 \pm 0.19 \mathrm{a}$ \\
MWT & $3,030 \pm 0.43 \mathrm{a}$ \\
OPT & $2,998 \pm 0.31 \mathrm{a}$
\end{tabular}

Note: The average values of treatments marked with the same letters show don not significant difference at the $5 \%$ test level according to Duncan's multiple range test.

Generally, the HMT and HPT modifications increased the strength of the starch gel. This was in agreement to the reported HMT modification on the sweet potato starch with $25 \%$ moisture content at temperature $110^{\circ} \mathrm{C}$ for 8 hours and on cassava starch and pinhao starch obtained from HPT modification with moisture content $22 \%$ at temperature $120^{\circ} \mathrm{C}$ for 2 hours [14]. The HMT and HPT modifications increased the crosslinking between starch chains especially in the amylose fraction $[14,16]$. Therefore, increased the formation of the junction zone of the matrix or tissue of the amylose bond leads to increase of the gel strength. This result was in agreement to the study using a similar method on wheat reported elsewhere [26]. This MWT modification caused the increase in the recrystallization of amylopectin in starch to lead to the improved of the gel strength.

The result of this study showed that the treatments tended to increase gel strength. However, this improvement was not significantly different compared to the native starch. This assumed due to apparently influenced by the occurrence of partial gelatinization at high temperatures and was not enough time required for the transformation of some of the starch structure to form a gel [11]. Also, the radiation energy might cause some starch granules disintegrated lead to hardly form a gel [26].

\subsubsection{Freeze-Thaw Stability (Syneresis Percentage)}

Taro Semir starch obtained from HMT and HPT modifications offered a significantly different effect compared to the MWT and OPT modifications, and the native taro Semir starch, as shown in Table 5.

The syneresis percentage on Taro Semir starch obtained from HMT modification was not significantly different compared to the starch obtained from HPT modification. Similarly, taro Semir starch obtained from MWT modification did not differ significantly compared to the starch obtained from the OPT modification. Compared to the native starch, the modified treatments decreased the syneresis percentage of the native taro starch. The HMT and HPT modifications provided more effective in reducing syneresis than MWT and OPT modifications. This might due to HMT and HPT modifications provide larger damage to the starch granules compared to the HMT and HPT modifications [1]. Usually, physical modifications decrease the starch syneresis. The lowest value of syneresis obtained from HMT and HPT modifications indicated that starch has a greater freeze-thaw stability or more stable the syneresis against frozen storage temperatures. Thus, taro Semir starches obtained from HMT and HPT modifications offered an excellent stability against frozen temperature storage. 
Table 5. Syneresis percentage of native and modified taro Semir starch

\begin{tabular}{cc}
\hline Treatment & Syneresis (\%) \\
\hline Native & $45.51 \pm 2.31 \mathrm{c}$ \\
HMT & $5.39 \pm 2.31 \mathrm{a}$ \\
HPT & $0.00 \pm 0.00 \mathrm{a}$ \\
MWT & $34.39 \pm 5.66 \mathrm{~b}$ \\
OPT & $32.68 \pm 3.41 \mathrm{~b}$ \\
\hline
\end{tabular}

Note: The average values of treatments marked with the same letters show do not a significant difference at the $5 \%$ test level according to Duncan's multiple range test.

Hydrothermal modification treatments such as HMT and HPT causes the amylopectin molecule rearrangement and produces more hydroxyl bonds that absorb more water and reduce syneresis [21]. Taro Semir starch obtained from HMT and HPT modifications assumed to have more hydroxyl bond indicated by larger damage occurred to absorb more water compared to MWT and OPT modifications. This result was in agreement with the taro starch obtained from HMT and HPT modifications reported elsewhere [21].

The MWT modification reduced starch syneresis due to microwave energy generated fast and uniform characteristic of starch. Thus, this treatment increased the strength of hydrogen bonding due to the interaction between the amylose-amylose chain and amylose-amylopectin. The OPT modification also reduced the starch syneresis. The effect of OPT modification on starch synthesis was assumed due to the involvement of $\mathrm{Na}^{+}$ions with less adsorbed water lead to decrease the syneresis. This related to the $\mathrm{Na}^{+}$ions having relatively large electrons and asymmetric structures causing relatively weak retrogradation [20].

\subsection{Gelatinization Profile}

Figure 1 showed the gelatinization profile indicating the behavior of starch viscosity observed before, during, and after the gelatinization process of the native taro Semir starch (pure starch) and modified taro Semir starches. This gelatinization profile of starch was analyzed using the Rapid Visco Analyzer (RVA) [21].

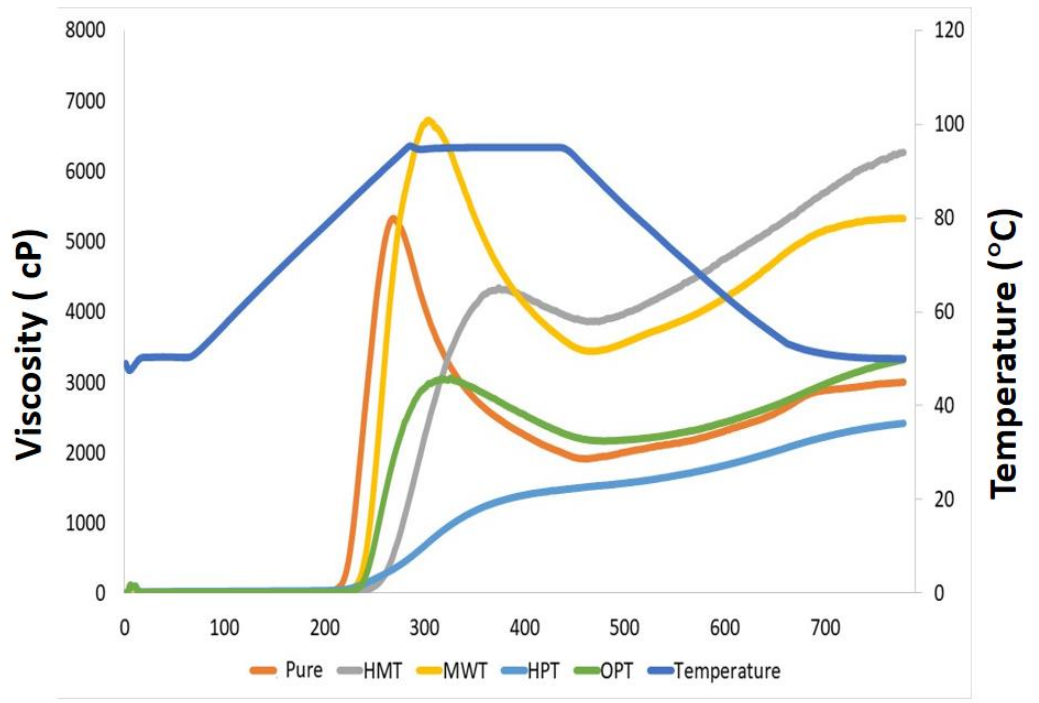

Time (minutes)

Figure 1. The curve of the gelatinization profile of native and modified taro Semir starch.

This observation provided properties of starches under investigation include the initial temperature of gelatinization, peak viscosity, heat paste viscosity, breakdown viscosity, cold paste viscosity, and setback viscosity. This result showed that the native and modified taro starch obtained MWT were belonged to A-type gelatinization profile indicated by a high peak viscosity and rapidly decline viscosity during heating. The profile curve of taro Semir starch obtained from HMT and OPT modifications were belonging to B-type gelatinization profile indicated by lower viscosity peak and the viscosity during 
warming did not rapidly decline. The profile curve of starch obtained from HPT modification was belong to C-type gelatinization profile indicated by weak viscosity peak and slowly decline and even increase during heating. The alteration of the gelatinization profile was caused by starch granules modification occurred by resetting of the double helical chains of starch crystals lead to improved crystallinity compared to native starch [16]. The significant change observed on the gelatinization profile of the starch obtained from the HPT modification indicated that this process capable to convert A-type into C-type starch. A-type, B-type and C-type starches indicated for the starch possessing high, medium and limited development ability, respectively [3].

\subsubsection{The Initial Gelatinization Temperature}

The initial gelatinization temperatures of modified taro Semir starches were significantly different from native taro starch, as shown in Table 6. The increased gelatinization temperature was associated with the decrease of swelling volume [6]. All treatments were able to increase the initial gelatinization temperature of starch taro. Starch obtained from HMT modification offered the highest increase in the initial gelatinization temperature. It was probably due to prolonged treatment (16 hours) and limited moisture content. This treatment was able to prevent the gelatinization that only occurred on the concentric rings on the outside of the granules. Therefore, the original granules remain crystalline and stable [1]. As shown in Table 6, the starch obtained from all treatments increased their initial gelatinization temperature. In contrast, the increase of the initial gelatinization temperature of the starch obtained from HMT modification was significantly different compared to the starch obtained from MWT modification. The initial temperature of gelatinization given by each treatment might derive from a different mechanism.

Also observed that the increase in the initial gelatinization temperature occurred for the taro starch obtained from HMT modification. The presence of molecular interactions in the amorphous and crystalline parts formed strong structures with hydrogen bonds. This encouraged interactions between the amylose and amylopectin chains in the granular structure established more compact structure [25]. This result in accordance with the HMT modification on sweet potato starch reported elsewhere [3,25]. Similarly, the initial gelatinization temperature of the starch was increased for the starch obtained from the HPT modification. This might due to the formation of amylose inter-amorous association in the amorphous parts lead to strong starch granules structure [8]. This result was in agreement to study reported elsewhere [14], respectively for cassava starch and pinhao starch.

Table 6. The initial gelatinization temperature of native and modified taro Semir starch

\begin{tabular}{cc}
\hline Treatment & Initial Gelatinization Temperate $\left({ }^{\circ} \mathbf{C}\right)$ \\
\hline Native & $78.28 \pm 1.56 \mathrm{a}$ \\
HMT & $83.65 \pm 0.77 \mathrm{c}$ \\
HPT & $82.22 \pm 0.66 \mathrm{bc}$ \\
MWT & $82.11 \pm 0.11 \mathrm{~b}$ \\
OPT & $82.65 \pm 0.88 \mathrm{bc}$ \\
\hline
\end{tabular}

Note: The average values of treatments marked with the same letters show no significant difference at the $5 \%$ test level according to Duncan's multiple range test.

The taro Semir starch obtained from MWT modification also offered an increase of the initial gelatinization temperature. The MWT modification enhanced crystallinity initiated by the growth of amylopectin in the crystalline area and interacts with amylose molecules in the amorphous are [12]. The increase in the initial gelatinization temperature was indicated by rearrangement of intramolecules in starch granules during the MWT modification. This result was in agreement to results using a similar method for normal cornstarch, maize waxy starch and amylomaize starch reported elsewhere [20]. Similarly, starch obtained from the OPT modification resulted in an increase of the initial gelatinization temperature. This might due to the ion $\mathrm{SO}_{4}{ }^{2-}$ with a symmetrical structure to preserve and strengthen the hydrogen bonds of the starch molecules. Hence, it hindered the interaction of starch with water molecules. Therefore, the enhanced hydrogen bonding leads to the increase of the gelatinization temperature [27]. This result is in agreement to the study using a similar method on the cornstarch reported elsewhere [15]. 


\subsubsection{The Peak Viscosity}

Table 7 showed the peak viscosity of the native taro Semir starch compared to the modified Taro Semir starch. The peak viscosity of the starch obtained from the HMT, HPT, and OPT modification decreased compared to the peak viscosity of the native starch, except the starch obtained from MWT modification. The HPT modification offered the lowest peak viscosity might due to given pressure formed layers outside of the starch granules leads to hinder the development of starch granules. While for the HMT and OPT modifications offered slightly decreased in the peak viscosity might due to the interaction between water molecules, amylose, and amylopectin occurring in starch granules through hydrogen bonds [28]. Therefore, this interaction derived rearrangement of the starch granule structure, i.e. the bonds were formed between amylose-amylose, amylose-amylopectin, and amylopectin-amylopectin. These bonds improved the starch granule structure resulted in decreasing peak viscosity. Instead, In addition, the decrease in peak viscosity might due to the formation of complex amylose and fat formations during the modification process [17]. This result was in agreement to the study using similar treatment for the sweet potato starch reported elsewhere $[3,26]$.

Table 7. The peak viscosity of native and modified taro Semir starch

\begin{tabular}{cc}
\hline Treatment & Peak Viscosity (cP) \\
\hline Native & $5,354.50 \pm 192.69 \mathrm{~d}$ \\
HMT & $4,349.17 \pm 192.61 \mathrm{c}$ \\
HPT & $1,456.67 \pm 48.50 \mathrm{a}$ \\
MWT & $6,748.17 \pm 186.08 \mathrm{e}$ \\
OPT & $3,073.50 \pm 386.30 \mathrm{~b}$
\end{tabular}

Note: The average values of treatments marked with the same letters show no significant difference at the $5 \%$ test level according to Duncan's multiple range test.

The peak viscosity of the starch obtained from the OPT modification also decreased might due to the formation of complex amylose and fat formations. In contrast, the peak viscosity of starch obtained from HPT modification was very sharp compared to other treatments. This result was in agreement to the study using a similar method of modification on potato starch and cornstarch, and on cassava and pinhao starches, and Dioscorea alata starch reported elsewhere $[15,14,19]$. The heating process using an autoclave generated a layer around the outer part of the partially sterilized starch granule. This layer functioned as a barrier to the incoming water and inhibiting gelatinization and pasting processes [11]. In contrast, the MWT was the only modification process that offered an increased on the peak viscosity. This might be due to the disintegration of starch granules and the re-association of amylopectin molecules and gradually undergoes gelatinization due to the vibrational motion of water molecules during microwave heating [21].

\subsubsection{The Breakdown Viscosity}

Table 8 showed the breakdown viscosity of native and modified taro Semir starches. The breakdown viscosity of the native starch and the starch obtained from MWT modification were not significantly different. In contrast, breakdown viscosities of taro Semir starch obtained from HMT, HPT, and OPT modifications were significantly different. However, the breakdown viscosity of the starch obtained from MWT modification only slightly changed from native starch. This indicated that the stability of starch against heating and stirring.

Table 8. The breakdown viscosity of native and modified taro Semir starches

\begin{tabular}{cr}
\hline Treatment & Breakdown Viscosity (cP) \\
\hline Native & $3,453.67 \pm 154.55 \mathrm{~d}$ \\
HMT & $494.00 \pm 33.81 \mathrm{~b}$ \\
HPT & $24.67 \pm 8.39 \mathrm{a}$ \\
MWT & $3,306.17 \pm 150.38 \mathrm{~d}$ \\
OPT & $932.67 \pm 130.40 \mathrm{c}$ \\
\hline
\end{tabular}

Note: The average values of treatments marked with the same letters show no significant difference at the $5 \%$ test level according to Duncan's multiple range tests 
The significant decreased in the breakdown viscosity for the starches obtained from HMT, HPT, and OPT modifications related to the stability of the starch paste during the heating and stirring process. Thus, the decrease in viscosity or breakdown viscosity during heating indicated that the starch more stable against heating and stirring and lead to form a paste [6].

The decreased of viscosity breakdown on taro starch obtained from the OPT modification might due to the increase of regularity of the crystalline matrix and the formation of a complex between amylose and fat during the process of modification. This result was in agreement to the study using a similar method on potato and cornstarch reported elsewhere [15]. While for the decreased of the breakdown viscosity of starch obtained from HMT modification might due to the regularity of the crystalline matrix and the formation of amylose-lipid complexes that decreases the swelling capacity of granular and improved the pasta stability during heating [17]. This result was in agreement to the study using a similar method on sweet potato reported elsewhere $[3,25]$.

In contrast, the lowest breakdown viscosity was obtained from the starch modified by HPT modification. This might due to the heating occurred in an autoclave created a layer outside of the starch granules [11]. This result was in agreement to the study using a similar method on cassava and pinhao starches reported elsewhere [14].

\subsubsection{The Setback Viscosity}

Table 9. showed the setback viscosity of native and modified taro Semir starches. The setback viscosity of the native taro Semir starch was not significantly different from taro starch obtained from HPT and OPT modifications. In contrast, taro starches obtained from MWT and HMT modifications were significantly deferent compared to native starch.

Table 9. The setback viscosity of native and modified taro Semir starch

\begin{tabular}{cc}
\hline Treatment & Viscosity Setback (cP) \\
\hline Native & $1,095.33 \pm 108.79 \mathrm{ab}$ \\
HMT & $2,413.00 \pm 165.85 \mathrm{~d}$ \\
HPT & $974.33 \pm 2.47 \quad \mathrm{a}$ \\
MWT & $1,888.33 \pm 74.13 \mathrm{c}$ \\
OPT & $1,181.17 \pm 101.93 \mathrm{~b}$ \\
\hline
\end{tabular}

Note: The average values of treatments marked with the same letters show no significant difference at the $5 \%$ test level according to Duncan's multiple range test.

The results of this study showed that native taro starch possessed similar retrogradation capability compared to the starch obtained from HPT and OPT modifications. However, the taro Semir starch obtained from HPT modification was significantly different retrogradation capability compared to the starch obtained from the OPT modification.

In contrast, the starches obtained from MWT and HMT modifications offered significantly different viscosity setback compare to native taro starch. This indicated that probably occurred retrogradation of starch during cooling [25]. The higher the setback value indicated the higher possibility to forms a gel (increase viscosity) during cooling. Thus, the improvement on the value of the setback viscosity indicated that highly possible for the starch experienced a retrogradation. The increase of the viscosity setback on starch obtained from HMT modification might due to changes of the structural arrangement in starch molecules. This initiated from modification of starch through alteration of the hydroxyl group arrangement caused the hydrogen bonds on the starch granules and retrograded [25]. In addition, apart from the amylose re-association, recrystallization occurred in the short chain of the straight amylopectin derived from the long chain degradation of amylopectin during HMT modification [17]. This result was in agreement to the study using a similar method on sweet potato starch reported elsewhere [3,25].

It was also perceived that the increase of the setback viscosity of starch obtained from MWT modification was due to the reaggregation of starch granules indicating the reassociation of the amylopectin branch chain. 


\section{Conclusions}

It was a highlight that thermal modification under investigation offered significant alteration on the swelling volume, solubility, the water absorption capacity, percentage of syneresis, gelatinization initial temperature, peak viscosity, breakdown viscosity, and setback viscosity, but was not significant to the gel strength. It was concluded that the taro Semir starch obtained from HMT modification process was considered well-performed with the following characteristics: the swelling volume of $6.57 \pm 0.80$ $\mathrm{mL} / \mathrm{g}$, the solubility of $5.80 \pm 0.29 \%$, the water absorption capacity of $2.59 \pm 0.09 \mathrm{~g} / \mathrm{g}$, the gel strength of $3,518 \pm 0.17 \mathrm{gF}$, the syneresis percentage of $5.39 \pm 2.31 \%$, the initial gelatinization temperature of 83.65 $\pm 0.77^{\circ} \mathrm{C}$, the peak viscosity $4,349.17 \pm 192,61 \mathrm{cP}$, the breakdown value $494 \pm 33.81 \mathrm{cP}$, and the setback value $2,413 \pm 165.85 \mathrm{cP}$.

Funding: This research was funded by HIU grants of Padjadjaran University in the year of 2017.

Acknowledgments: We thank the Directorate of Research, Community Services and Innovation (DRPMI) of Universitas Padjadjaran for funding this research under the grants of Basic Research for Beginner Lecturer in the year of 2017.

Conflicts of Interest: The authors declare there is no conflict of interest.

\section{References}

1. Hamzah, Y.; R. Siti A. Effect of heat moisture treatment on molecular structure and thermal properties of taro starch (Colocasia esculenta sp.) in UMT 11 th International Annual Symposium on Sustainability Science and Management, Terengganu, Malaysia. 2012; pp. 526-531, e- ISBN 978-967-5366-93-2.

2. Karmakar, R.; Ban, D.K.; Ghosh, U. Comparative study of native and modified starches isolated from conventional and nonconventional sources. Int. Food Res. J. 2014, 21, 597-602.

3. Collado, L.S.; Mabesa, L.B.; Oates, C.G.; Corke, H. Bihon-type noodles from heat-moisture-treated sweet potato starch. J. Food Sci. 2001, 66, 604-609, doi: 10.1111/j.1365-2621.2001.tb04608.x.

4. Tan, H.-Z.; Li, Z.-G.; Tan, B. Starch noodles: History, classification, materials, processing, structure, nutrition, quality evaluating and improving. Food Res. Int. 2009, 42, 551-576, doi:10.1016/j.foodres.2009.02.015.

5. Njintang, Y.N.; Scher, J.; Mbofung, C.M.F. Physicochemical, thermal properties and microstructure of six varieties of taro (Colocasia esculenta L. Schott) flours and starches. J. Food Eng. 2008, 86, 294-305, doi:10.1016/j.jfoodeng.2007.10.006.

6. Huang, C.-C.; Lai, P.; Chen, I.-H.; Liu, Y.-F.; Wang, C.-C. Effects of mucilage on the thermal and pasting properties of yam, taro, and sweet potato starches. LWT-Food Sci. Technol. 2010, 43, 849-855, doi: 10.1016/j.lwt.2009.11.009.

7. Pérez, E.; Schultz, F.S.; de Delahaye, E.P. Characterization of some properties of starches isolated from Xanthosoma sagittifolium (tannia) and Colocassia esculenta (taro). Carbohydr. Polym. 2005, 60, 139-145, doi:10.1016/i.carbpol.2004.11.033/.

8. Moorthy, S.N. Effect of steam pressure treatment on the physicochemical properties of Dioscorea starches. J. Agric. Food Chem. 1999, 47, 1695-1699, doi:10.1021/if971082m.

9. Aprianita, A.; Vasiljevic, T.; Bannikova, A.; Kasapis, S. Physicochemical properties of flours and starches derived from traditional Indonesian tubers and roots. J. Food Sci. Technol. 2014, 51, 3669-3679, doi:10.1007/s13197012-0915-5.

10. Sit, N.; Misra, S.; Deka, S.C. Characterization of physicochemical, functional, textural and color properties of starches from two different varieties of taro and their comparison to potato and rice starches. Food Sci. Technol. Res. 2014, 20, 357-365, doi:10.3136/fstr.20.357.

11. Hormdok, R.; Noomhorm, A. Hydrothermal treatments of rice starch for improvement of rice noodle quality. LWT-Food Sci. Technol. 2007, 40, 1723-1731, doi:10.1016/j.lwt.2006.12.017.

12. Zhang, J.; Wang, Z.; Shi, X. Effect of microwave heat/moisture treatment on physicochemical properties of Canna edulis Ker starch. J. Sci. Food Agric. 2009, 89, 653-664, doi:10.1002/jsfa.3497.

13. Neelam, K.; Vijay, S.; Lalit, S. Various techniques for the modification of starch and the applications of its derivatives. Int. Res. J. Pharm. 2012, 3, 25-31.

14. Klein, B.; Pinto, V.Z.; Vanier, N.L.; da Rosa Zavareze, E.; Colussi, R.; do Evangelho, J.A.; Gutkoski, L.C.; Dias, A.R.G. Effect of single and dual heat-moisture treatments on properties of rice, cassava, and pinhao starches. Carbohydr. Polym. 2013, 98, 1578-1584, doi:j.carbpol.2013.07.036. 
15. Pukkahuta, C.; Suwannawat, B.; Shobsngob, S.; Varavinit, S. Comparative study of pasting and thermal transition characteristics of osmotic pressure and heat-moisture treated corn starch. Carbohydr. Polym. 2008, 72, 527536, doi:10.1016/j.carbpol.2007.09.024.

16. da Rosa Z.E.; Dias, A.R.G. Impact of heat-moisture treatment and annealing in starches: A review. Carbohydr. Polym. 2011, 83, 317-328, doi:10.1016/j.carbpol.2010.08.064.

17. Hoover, R.; Vasanthan, T. Effect of heat-moisture treatment on the structure and physicochemical properties of cereal, legume, and tuber starches. Carbohydr. Res. 1994, 252, 33-53, doi:10.1016/0008-6215(94)90004-3.

18. Vieira, F.C.; Sarmento, S.B.S. Heat-moisture treatment and enzymatic digestibility of Peruvian carrot, sweet potato and ginger starches. Starch-Stärke 2008, 60, 223-232, doi:10.1002/star.200700690.

19. Syamsir, E.; Hariyadi, P.; Fardiaz, D.; Andarwulan, N.; Kusnandar, F. Pengaruh proses heat-moisture treatment (hmt) terhadap karakteristik fisikokimia pati [Effect of Heat-Moisture Treatment (HMT) Process on Physicochemical Characteristics of Starch]. J. Teknol. dan Ind. Pangan 2012, 23, 100-106.

20. Luo, Z.; He, X.; Fu, X.; Luo, F.; Gao, Q. Effect of microwave radiation on the physicochemical properties of normal maize, waxy maize and amylomaize V starches. Starch-Stärke 2006, 58, 468-474, doi: 10.1002/star.200600498.

21. Deka, D.; Sit, N. Dual modification of taro starch by microwave and other heat moisture treatments. Int. J. Biol. Macromol. 2016, 92, 416-422, doi:10.1016/j.ijbiomac.2016.07.040.

22. Zondag, M.D. Effect of microwave heat-moisture and annealing treatments on buckwheat starch characteristics, Master of Science Degree, University of Wisconsin-Stout, United States, May, 2003.

23. Chen, Z.; Schols, H.A.; Voragen, A.G.J. Starch granule size strongly determines starch noodle processing and noodle quality. J. Food Sci. 2003, 68, 1584-1589, doi:10.1111/i.1365-2621.2003.tb12295.x.

24. Visakh, P.M.; Yu, L. Starch-based blends, composites and nanocomposites; Royal Society of Chemistry, 2015; ISBN 1782622799.

25. Pranoto, Y.; Rahmayuni; Haryadi; Rakshit, S.K. Physicochemical properties of heat moisture treated sweet potato starches of selected Indonesian varieties. Int. Food Res. J. 2014, 21.

26. Palav, T.; Seetharaman, K. Impact of microwave heating on the physico-chemical properties of a starch-water model system. Carbohydr. Polym. 2007, 67, 596-604, doi:10.1016/j.carbpol.2006.07.006.

27. Wang, W.; Zhou, H.; Yang, H.; Zhao, S.; Liu, Y.; Liu, R. Effects of salts on the gelatinization and retrogradation properties of maize starch and waxy maize starch. Food Chem. 2017, 214, 319-327, doi:10.1016/i.foodchem.2016.07.040.

28. Varatharajan, V.; Hoover, R.; Liu, Q.; Seetharaman, K. The impact of heat-moisture treatment on the molecular structure and physicochemical properties of normal and waxy potato starches. Carbohydr. Polym. 2010, 81, 466-475, doi:10.1016/j.carbpol.2010.03.002. 